\title{
NBSIR 75.709 \\ Design and Fabrication of an Integrally Illuminated Runway Distance Marker Using Subminiature Incandescent Lamps
}

M. R. Freund, W. F. Mullis

Illuminating Engineering Group

Optical Radiation Section

Heat Division

Institute for Basic Standards

National Bureau of Standards

May 1975

Final Report

Prepared for

Ships Installation Division

Naval Air Systems Command

Department of the Navy

Washington, D. C. 20360 
NBSIR 75-709

\section{DESIGN AND FABRICATION OF AN INTEGRALLY ILLUMINATED RUNWAY DISTANCE MARKER USING SUBRINIATURE INCANDESCENT LAMPS}

M. R. Freund, W. F. Mullis

Illuminating Engineering Group

Optical Radiation Section Heat Division

Institute for Basic Standards

National Bureau of Standards

May 1975

Final Report

Prepared for

Ships Installation Division

Naval Air Systems Command

Department of the Navy

Washington, D. C. 20360

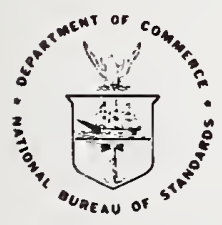

U.S, DEPARTMENT OF COMMERCE, Rogers C.B. Morton. Secretary

NATIONAL BUREAU OF STANDARDS, Richard $w$. Roberts, Oirector 


\section{PREFACE}

At the request of the Naval Air Systems Command, Department of the Navy, the National Bureau of Standards designed and fabricated an integrally illuminated runway distance-to-go marker using subminiature incandescent lamps. The work was initiated in an effort to improve the performance of the markers over existing units in terms of conspicuity, energy saving, extent of maintenance required, and in regard to their impact mass. The prototype model fabricated is not considered a final engineered design but is described primarily to illustrate the design concept. The opinions, findings, and conclusions in this report are those of the authors and are not necessarily those of the Naval Air Systems Command. 


\section{CONTENTS}

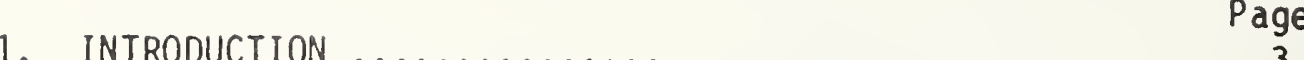

2. PROTOTYPE MARKER DESIGN $\ldots \ldots \ldots \ldots \ldots \ldots \ldots \ldots \ldots \ldots$

2.1 Mechanical ............................. 4

2.2 Electrical ............................. 5

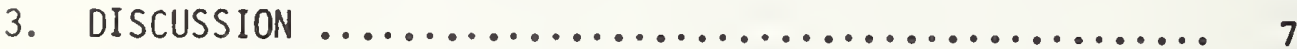

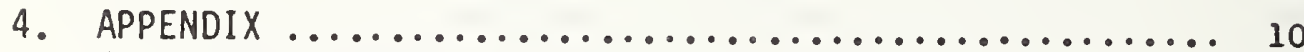

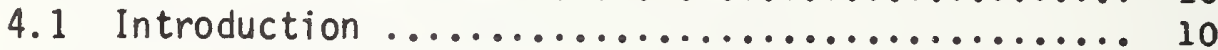

4.2 Alternate Construction ................... 10

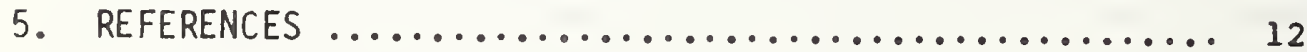

\section{ILLUSTRATIONS}

1 Daylight and Night Photographs of NBS Prototype Integrally Illuminated Runway Distance Marker ....... 13

2 Detail of Runway Distance Marker Construction ......... 14

A1 Cross-sectional Sketch of Alternative Method \#1 of Constructing Integrally Illuminated Runway Distance Marker Using Subminiature Incandescent Lamps ........ 15

A2 Cross-sectional Sketch of Alternative Method \#2 of Constructing Integrally Illuminated Runway Distance Marker Using Subminiature Incandescent Lamps

\section{TABLES}

1 Load-Voltage Characteristics of Existing Transformers 6

2 Estimated Number of Lamps and Power Required Per Numer al 


\section{INTRODUCTION}

Two types of distance-to-go markers are currently in use at military and joint-use (civil and military) airports to indicate the runway-remaining distance. The two types can be classified as externally illuminated and internally illuminated units. The markers are spaced at 1000 foot intervals and indicate the distance to the end of the runway in thousands of feet. The externally illuminated marker was the first type to be used and consists basically of a "billboard" type sign painted orange with a white numeral. It is illuminated at night with two 75-watt, 120-volt, PAR 38, floodlights, one located adjacent to each side of the sign, (see NBS Report 5466, dated September 1957). The internally illuminated marker is the type presently prescribed as the Navy Standard (NAEC Airfield Visual Aids Bulletin \#1, dated 16 Nov. 1970) and consists of an aluminum housing with translucent plastic side panels and internally mounted incandescent lamps. A transparent yellow numeral is displayed on a black opaque background. Six 75-watt, 120-volt lamps are used to illuminate the numerals of the sign. (NBS Report 6904, dated July 1960).

Although the present markers have proved fairly satisfactory, concern has recently been voiced in regard to the extent of maintenance required for the units, and in regard to their weight or impact mass. Also, with advances in technology, the question has been raised as to whether the markers might be improved in regard to legibility and power requirements. Further, it has been suggested that the painted surface type be replaced with an internally illuminated type, either of the present design or of a new design.

Because of these factors, the National Bureau of Standards was requested to design and fabricate a marker that would effectively alleviate as many of the above concerns as possible. The marker thus produced has been evaluated at the Naval Air Test Center, Patuxent River, Md. along with existing markers. Results of their evaluation is contained in NATC Report FT-73R-74 and indicates that the design concept of the marker is promising. The purpose of this report, therefore, is to describe the construction of the NBS-designed prototype marker. The prototype unit was not intended to be a final engineered design but was constructed to test the liqhting concept and durability features. Alternative methods of construction for reducing the impact mass of the marker while maintaining the design concept are described in the appendix. 


\subsection{MECHANICAL}

Except for the mounting hardware, (e.g., poles) lamps, and wiring, the sign is constructed of plastic materials. It consists of an integrally illuminated white plastic (acrylic) numeral laminated to an aviation orangecolored acrylic background panel which in turn is bonded to an opaque fiberglass panel. (See Figures 1 and 2). Two such signs are mounted back-to-back on poles having frangible couplings. The signs display a numeral or numerals on each side indicating the distance (in thousands of feet) to the respective ends of the pavement. The dimensions of each side of the prototype sign were 4 feet in height, 3 feet in width, and $11 / 16$ inch in thickness. The numerals of the sign were 40 inches high and 5 inches wide. A plastic adaptor is used to fasten the signs to the poles and to enclose the space between panels. The adaptor also serves to stiffen the plastic panels. The numeral is illuminated by surminiature incandescent lamps. The number of lamps for a particular panel depends on the numeral being displayed. For example, an "8" may take as many as 85-90 lamps, whereas a "l" may take only 40-45 lamps. The lamps are designated with the trade number 715. They have a $T-1 / 8$ bulb, pigtail leads, and are rated at 5 volts, 0.11 ampere, with 50,000 hour's 1 ife. The dimensions of the sign and the numerals were made in accordance with the requirements of Technical Manual, NAVAIR 51-50AAA-2, "Visual Lüinding Aids Design Standards Installations", dated I April 1966, except that the width of the background pane? was 3 feet instead of the 4 feet specified. The width was limited to the width of the plastic sheets available at the time of fabrication. The weight of the prototype two-sided sign was approximately 60 pounds exclusive of the priles and mounting hardware.

Specific details of the marker construction are shown in Figure 2. The lamps are rounted in the white numeral portion of the sign, approxinately 1 inch from each edge in holes drilled both through the orange background sheet and to a depth of $11 / 32$ of an inch into the numeral. The numeral is translucent and is $1 / 8$ inch thick, whereas the background is essentially opaque and is $1 / 4$ inch thick. The holes for receiving the lamps are $1 / 8$ inch in diameter. Wiring for the lamps is attached to the rear surface of the background panel with small screws and is soldered to the 
lamp leads (pigtails) at each hole location. The lamps are placed at 2 inch intervals (although sharp curves may require closer spacing) and thus outline the shape of the numeral. Bare 20-gage copper wire was used for the prototype model although flat-printed or ribbon circuitry would be preferable. The wiring is protected by a $1 / 16$ inch thick protective fiberglass sheet bonded to the background panel by use of a $1 / 4 \times 2$ inch plastic spacer strip bonded around the periphery of the sign. The spacer was used in order to provide clearance for the wiring. (If flat conductors are used the protective panel can be bonded directly to the background panel.)

\subsection{ELECTRICAL}

The electrical load requirements for the various marker panels differ as each numeral displayed requires a different number of lamps. The lamps are connected in parallel so that the current to the panel is directly proportional to the number of lamps required. For example, if an " 8 " is displayed containing 87 lamps, the current drawn at rated voltage ( 5 volts) would be 9.57 amperes or 47.9 watts of power, whereas, if a "l" is displayed requiring only 42 lamps, the current drawn under similar conditions, would be 4.6 amperes or 23 watts of power. Power for the distance markers is usually obtained from the edge-lighting or other series circuits. Since the current requirements for signs differ, a simple series/series isolating transformer can not be used in its conventional unsaturated mode. In addition, some dimming of the marker lights is desired as the runway lights are dimmed. However, for optimum performance, the range of dimming for the distance marker lights should not be as great as the dimming of the runway lights. Fortunately, some of the series transformers presently used for the runway lights have appropriate characteristics for powering the marker lights through an auxiliary step-down type transformer to obtain the required 5 volts. From NBS Report No. 6337, dated March 1959, "Output Characteristics of Three 200-watt Seriesseries Transformers with Multiple Lamps as Load", it is evident that all of the three 200-watt $6.6 \mathrm{~A} / \mathrm{S} .6 \mathrm{~A}$ series/ series, 5000-volt transformers described in that report and used to power the airport runway edge lights can also be used to power, the marker lights. These transformers, manufactured by three different companies (Jefferson Electric, Line Material, and AGA) have essentially the same shaped load-voltage characteristic curves, but differ slightly in the magnitude of their secondary voltage. An 
example of the differences are listed in Table I for step 5 (maximum current step) of the current regulator. The differences are essentially proportional for the other four dimning steps.

TAPLE I

Load-Voltage Characteristics of Existing Transformers

Output Voltage on Intensity Step 5

\begin{tabular}{cccc}
$\begin{array}{c}\text { Transformer } \\
\text { (watts) }\end{array}$ & $\begin{array}{c}\text { Line Material } \\
\text { Company }\end{array}$ & AGA & $\begin{array}{c}\text { Jefferson Electric } \\
\text { Company }\end{array}$ \\
\hline & & & 105 \\
50 & 85 & 90 & 90 \\
100 & 72.5 & 82.5 & 93
\end{tabular}

From these data, it is evident that step-down transformers having a ratio of about $15 / 1$ would be satisfactory for powering the marker signs from the Line Material transformer. However, transformers having ratios of about 16/1 and $18 / 1$ would be required to give the 5 volts required from the transformer manufactured by $A G A$ and the Jefferson Electric Company respectively. A tapped step-down transformer would accommodate the variations in transformers manufactured by the different comparies.

Calculations indicate that an average distance marker having a 75-watt load and operated from any of the above mentioned transformers, would be dimmed to about 60 to 70 percent of full current intensity, depending upon the type of transformer used, when the intensity setting is changed from step 5 to step 1; whereas the runway edge lights would be dinmed to 0.28 of full current intensity (data from NBS Report 6337).

A rough estimate of the quantity of lamps required for each numeral and the electrical load of the numeral is given in Table II. 
TABLE II

Estimated Number of Lamps and Power Required per Numeral

Numeral Displayed

Quantity of Lamps

Required
Power Consumed (Watts)

$\begin{array}{lll}0-96 & 53 \\ 1 & 92 & 23 \\ 2 & 42 & 50 \\ 3 & 90 & 48 \\ 4 & 88 & 41 \\ 5 & 74 & 52 \\ 6 & 96 & 50 \\ 7 & 90 & 37 \\ 8 & 67 & 48 \\ 9 & 87 & 50\end{array}$

A combination of two or more numerals would constitute the load on the power transformer at a given station along the runway. From these data it is seen that the minimum load for a single station would be of the order of 46 watts (2-ones) to a maximum of about 104 watts (2-fives). The load variations are of the same wattage range as given for the transformers in Table I. The secondary voltages of the transformers vary less than 58 with a load change from 50 to 100 watts. A 5 voltage variation to the different marker signs would result in an intensity difference of about 168, which for practical purposes is visually indistinguishable.

\section{DISCUSSION}

The design and construction of the marker described is simple, uses less electrical power than existing units, provides a high degree of legibility for both day and night operations, offers reduced maintenance features, and is compatible with existing airport runway electrical systems. From the standpoint of maintenance, the all-plastic construction should require little or no cleaning. Furthermore, the plastic was deemed to be durable because during the two years the prototype unit was installed at the Naval Air Test Center at Patuxent River, Md., no discoloration, fading, or other deterioration was detected. Also, from the standpoint of lamp life, the 50,000-hour life represents almost 6 years of continuous burning. If average operating time is $10-12$ hours per day, life of the marker, barring physical abuse, should be well over 10 years. 
As for night conspicuity in service, pilots judged the prototype as a considerable improvement over the existing marker and with a greater readability range. In clear weather resolution of the numeral is limited primarily by its size.

As for the daylight conspicuity, the NATC tests indicated that the NBS marker "did not demonstrate any improvement over the present marker". The pilots pointed out that all the markers tended to blend into the background. They further suggested that daylight contrast might be improved by adding a black border around the white numeral or perhaps placing the white numeral on a black panel.

Two basic questions arise from these suggestions. The first deals with detection range and distinguishing the whole sign from its surroundings while the second deals with recognition of the numeral displayed. As regards the first question, Judd and Yonemural studied the conspicuity of targets painted with international orange and with black against various backgrounds. They concluded that international orange is more conspicuous against a dark-foliage background; and black is more conspicuous than international orange for a lightfoliage background. For average foliage international orange is more conspicuous at large angular subtense (greater than 10 minutes of $\mathrm{arc}$ ); and black is more conspicuous at small subtense. They stated that "the virtue of international orange is that it is fairly conspicuous against all foliage backgrounds". The question then is under what background conditions and viewing angles are the signs used. The background runs the gamut in color from white to dark green to brcwn and all shades and hues between (snow, grass, forest, water, etc.). In addition, the angular subtense of the numerals displayed (stroke width 5 inches) can be considered as fairly small (about 1.5 minutes of arc at 1000 feet and 3 minutes at 500 feet). With this in mind, and if the background can be considered as "average foliage" then it would appear that international orange might maintain a slight superiority cver black for detection of the sign from the standpoint of backgrcund whereas black would be the superior finish from the stanojpint of size (angular subtense). Bear in mind that the differences in question for practical purposes are small.

On the other hand, the purpose of the sign is to convey information. Therefore, legibility of the numeral is as important as detection of the sign. Legibility is a function of the contrast between the numeral and its immediate surround. Usually, the greater the contrast, the easier, the numeral is to read. Since the greatest contrast exists between black and white ard sirice a white letter is used, this would suggest that the surrounding panel should be tlack. Consequently, there appears to be a conflict between optimum detection of the sign and legibility of the numeral. Either background appears to be adequate for the visibility ranges intended. 
The 60 pounds of weight of the prototype marker is probably comparable to existing signs and is considered greater than necessary or desired from the standpoint of impact mass. Therefore, following the fabrication and installaticn at Patuxent of the prototype, alternate designs which significartly reduce the weight of the unit were evolved. Details of the lighter units are given in the appendix.

Based upon the potential improvement of marker signs using the all plastic constructicn and the integrally illuminated concept with respect to lower maintenance, power consumption, and weight reduction, it is recommended that a sufficient number of these signs be fabricated to equip a full runway for further evaluation. The design conceft should also be extended to taxiway and apron guidance signs. 


\section{ALTERNATIVE METHODS OF CONSTRUCTION OF THE INTEGRALLY ILLUMINATED RLNWAY DISTANCE MARKER}

\subsection{INTRODUCTION}

In the preceaing report the prototype integrally illuminated runway distance marker was described. The lighting concept as well as the durability of the sign appears sound, based upon the field evaluation at the Naval Air Test Center, Patuxent River, Md. However, as was pointed cut in the report, the weight of the unit is of the order of 60 pounds. This weight is considered greater than needed or desiratle. To reduce damage to aircraft wher they collide with signs of this type, it is imperative that the mass of the signs be small and that their center of gravity be as near to the ground as possible. Consequently, alternative methods of constructing the NBS designed marker to reduce its impact mass and to lower its center of gravity follow. Using this method of construction, a sign of less than 40 pounds should be easily achieved.

\subsection{ALTERNATIVE CONSTRUCTION}

The alternate method of construction consists of using $1 / 8$, or $1 / 6$ inch, thick orange background panels instead of the $1 / 4$ inch panels used in the prototype. The panels are spaced parallel approximately $\mathrm{l}$ inch apart as shown in sketch, A-l or tapered slightly as shown in sketch A-2. The space between the panels is filled with a light-weight foam or honeycomb material for obtaining the necessary rigidity. The filler material should be of a type that bonds to the panels. The acrylic material for the numeral is increased to about $1 / 4$ to $5 / 16$ inch in thickness to accommodate the installation of the wiring and sub-miniature lamps. The numeral and background panels are then laminated together as previously described or the numeral is attached mechanically to the background if it is desirable to remove or replace numerals. A light-weight perforated aluminum U-shaped frame installed along the bottom edge of the panels completes the marker assembly. The U-frame carrying a pipe flange attaches to the poles having frangible couplings in the usual manner. This method of mounting keeps all of the relatively heavy structural members of the sign near the ground (12 to 16 inches) and thereby should result in less damage to an aircraft upon impact. Further, the all-plastic 
construction above the mounting should result in

a fixture that shatters more readily than existing signs. wiring for the marker sign is accomplished as described

for the prototype unit except that if removable numerals are desired, appropriate electrical connectors are added where the numerals are attached to the panels. 


\section{REFERENCES}

1. Judd, D.B. and Yonemura, G.T., Target Conspicuity and Its Dependence on Color and Angular S Lbtense for Gray and Foliage Surrounds, NBS Report 10-120, Nov'smber 1969. 

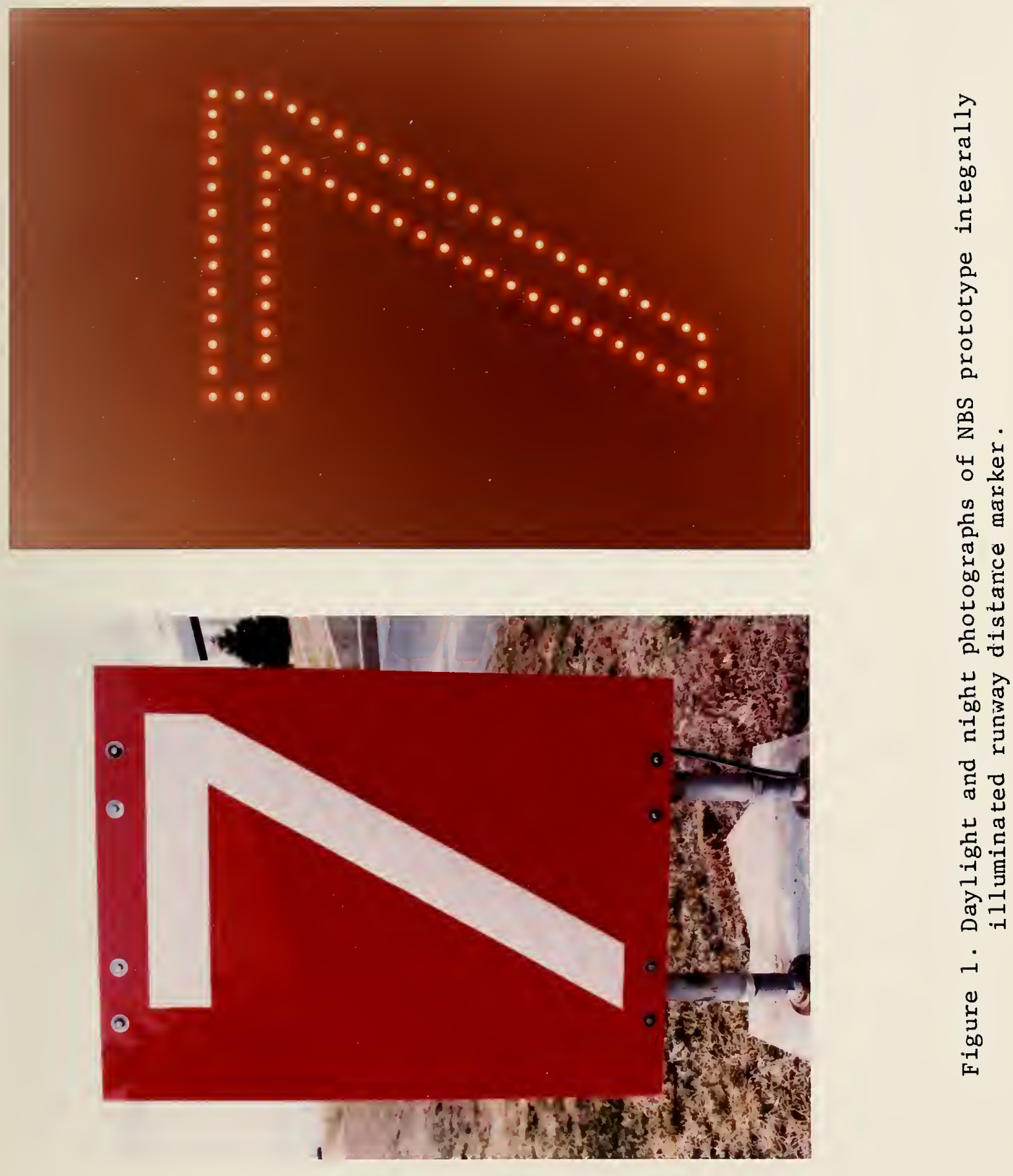


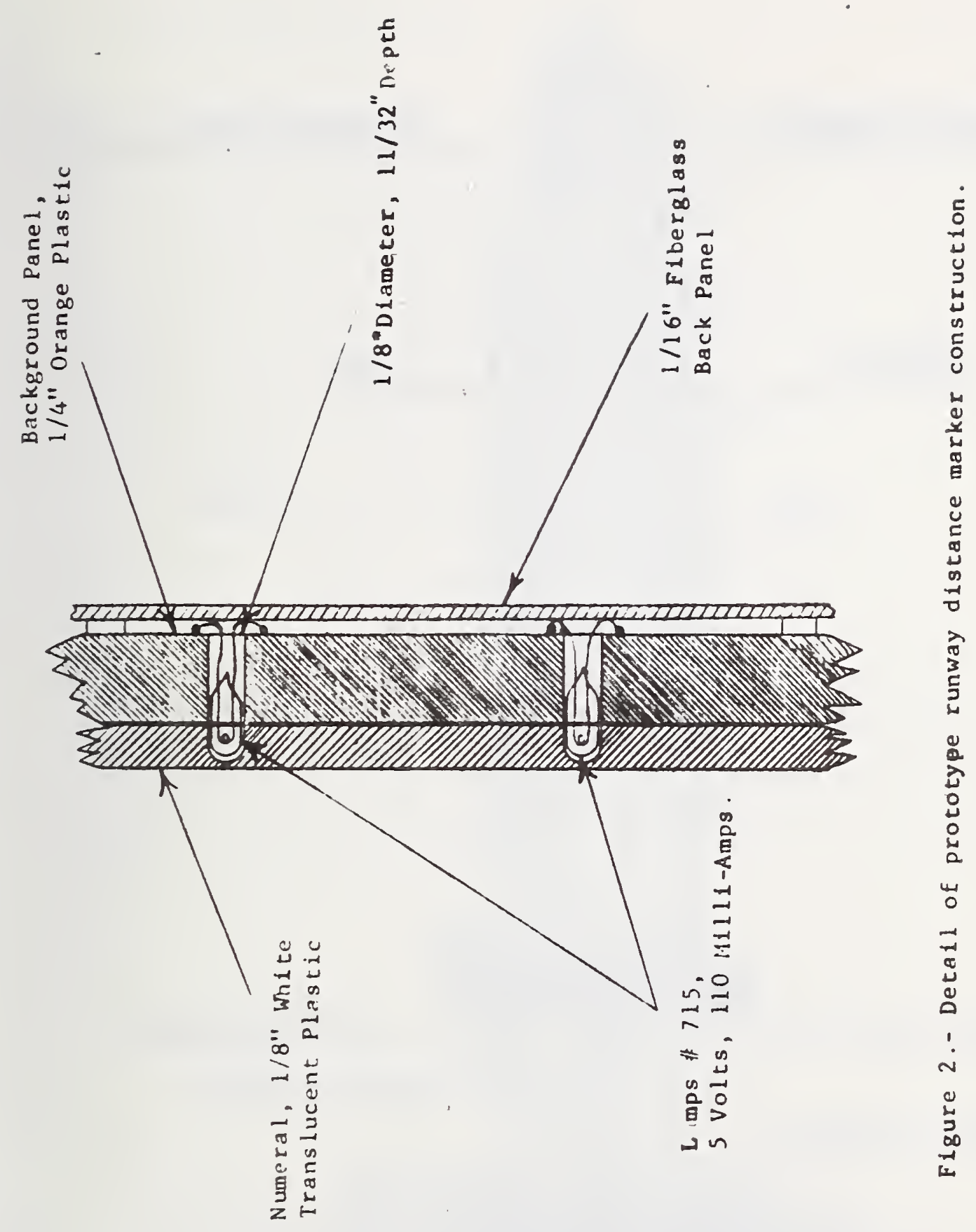




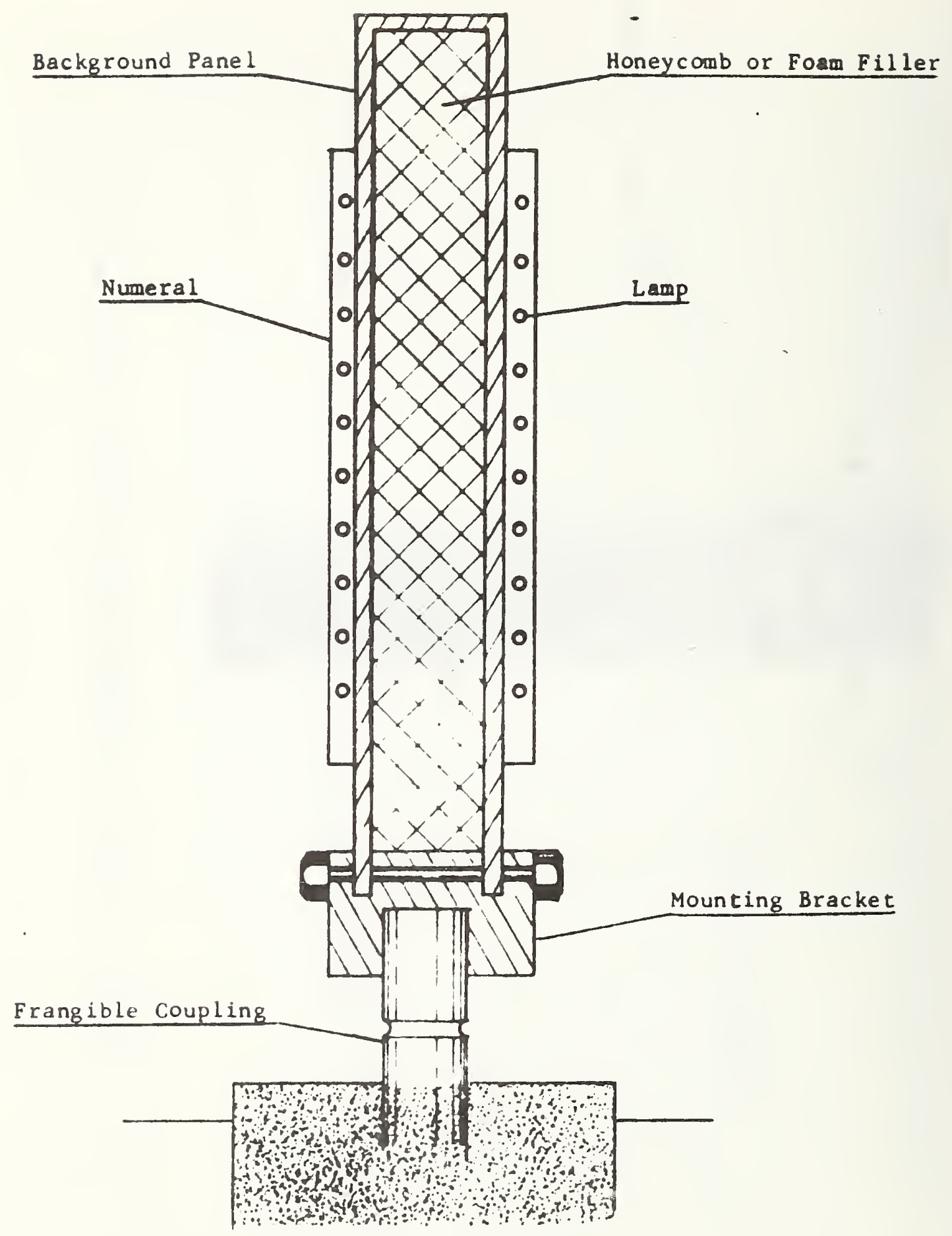

Figure A-1. Cross-sectional Sketch of Alternative Method \#1 of Constructing Integrally Illuminated Runway Distance Marker Using Subminiature Incandescent Lamps. 


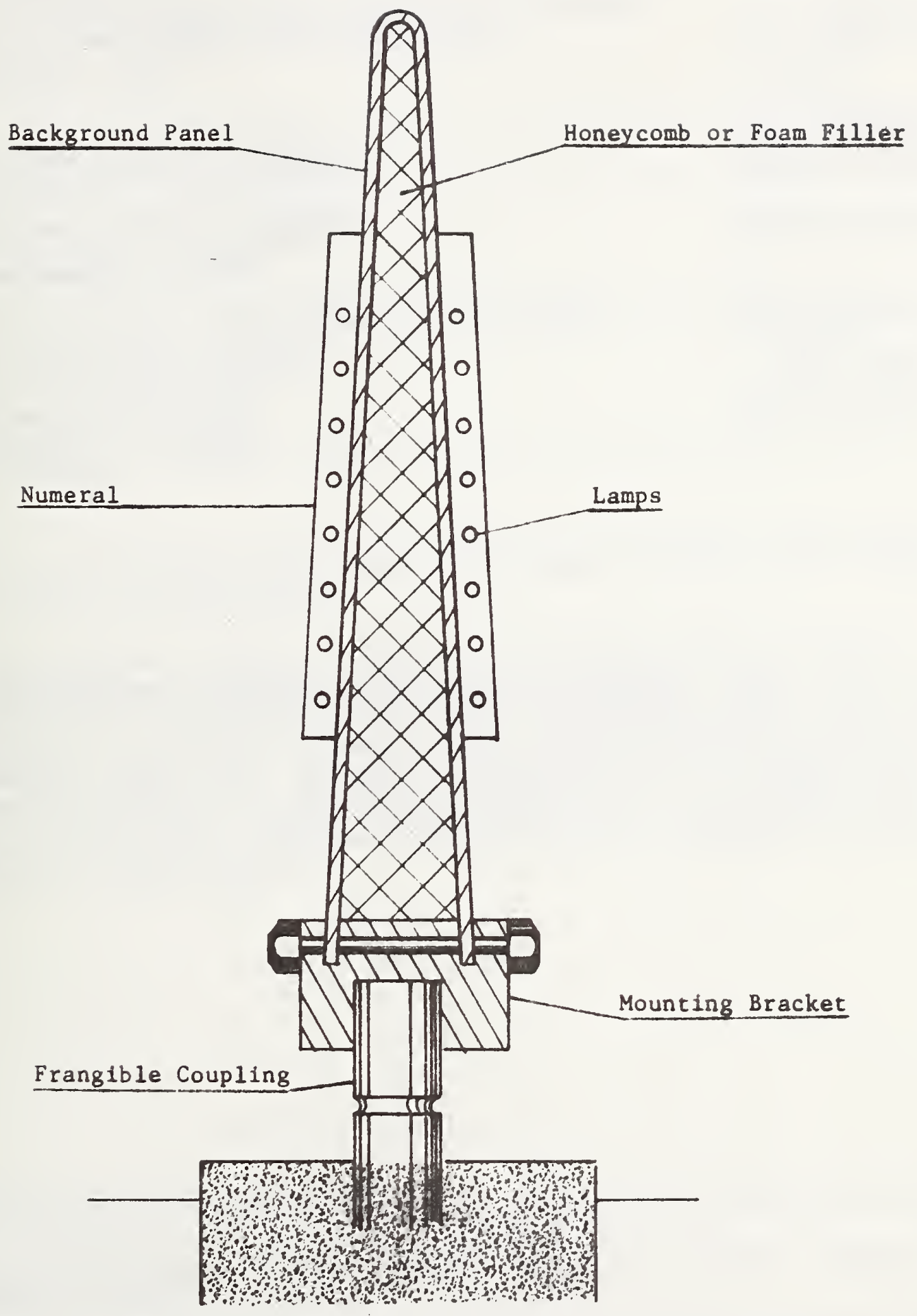

Figure A-2. Cross-sectional Sketch of Alternate Method \#2 of Constructing Integrally Illuminated Runway Distance Marker Using Subminlature Incandescent Lamps. 

NBS.IIAA IREV. 7.73 )

\begin{tabular}{|c|c|c|c|}
\hline $\begin{array}{l}\text { U.S. DEPT. OF COMM. } \\
\text { BIBLIOGRAPHIC DATA } \\
\text { SHEET }\end{array}$ & $\begin{array}{l}\text { 1. IMIBLICATION OR.RIEPORT NO. } \\
\text { NBSIR 75-709 }\end{array}$ & $\begin{array}{l}\text { 2. Gov't Accession } \\
\text { No. }\end{array}$ & 3. Recipient's Accession No. \\
\hline \multirow{2}{*}{\multicolumn{3}{|c|}{$\begin{array}{l}\text { 4. TITLF AND SUBTITLE } \\
\text { Design and Fabrication of an Integrally Illuminated } \\
\text { Runway Distance Marker Using Subminiature } \\
\text { Incandescent Lamps }\end{array}$}} & $\begin{array}{r}\text { 5. Publication Date } \\
\text { May } 1975 \\
\end{array}$ \\
\hline & & & $\begin{array}{l}\text { 6. Performing Organization Code } \\
221.12\end{array}$ \\
\hline \multicolumn{3}{|c|}{$\begin{array}{l}\text { 7. AUTHOR(S) } \\
\text { M. R. Freund and W. F. Mullis }\end{array}$} & $\begin{array}{l}\text { 8. Performing Organ. Report No. } \\
\text { NBSIR 75-709 }\end{array}$ \\
\hline \multirow{2}{*}{\multicolumn{3}{|c|}{$\begin{array}{l}\text { 9. PERFORMING ORGANIZATION NAMI: ANI) ADDRESS } \\
\text { NATIONAL BUREAU OF STANDAROS } \\
\text { DEPARTMENT OF COMMERCE } \\
\text { WASHINGTON, O.C. } 20234\end{array}$}} & 10. Project/Task/Work Unit No. \\
\hline & & & 11. Contract/Gtant No. \\
\hline \multirow{2}{*}{\multicolumn{3}{|c|}{$\begin{array}{l}\text { 12. Sponsoring (roanization Name and (omplete Address (Street, Cily, State, ZIP) } \\
\text { Ships Installation Division } \\
\text { Naval Air Systems Command } \\
\text { Department of the Navy } \\
\text { Washington, D. C. } 20360\end{array}$}} & $\begin{array}{l}\text { 13. Type of Report \& Period } \\
\text { Covered } \\
\text { Fina ], May, } 1975\end{array}$ \\
\hline & & & 14. Sponsoring $A_{B}$ ency Code \\
\hline
\end{tabular}

16. AlBSTRAC I (A 200-word or less factual summary of most sienificant information. It document includes a significant bibliography or literature survey, mention it here.)

A prototype integrally illuminated runway distance-to-go marker was developed using embedded subminiature incandescent lamps. The all-plastic construction of the marker offers improved performance over existing markers in respect to conspicuity, energy saving, reduced maintenance, and in regard to reduced impact mass. The marker is compatible with existing airport electrical systems. The unit was evaluated over a 2 year period at the Naval Air Test Center, Patuxent River, Md. and was selected as the most promising of those tested.

17. KEY WORI) (six to ewelve entries, alphabelical order, capitalize anly the first letter of the first key word unless a proper name; separated by semicolons)

Runway distance-to-go marker; airport conspicuity; contrast; readability range; legibility; color.

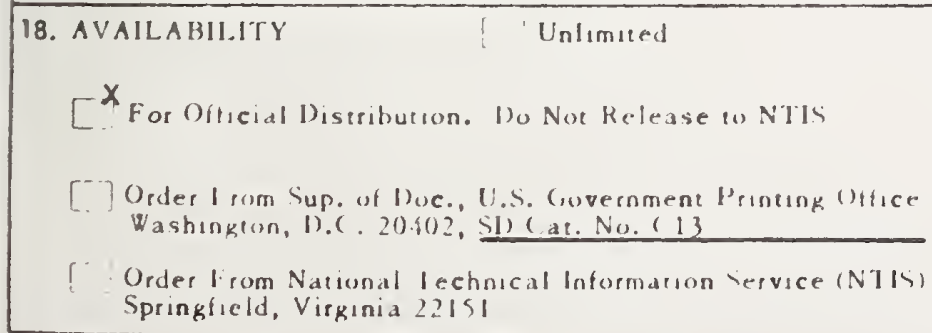

\begin{tabular}{|c|c|}
\hline $\begin{array}{l}\text { 19. SH:(1)RITY CL.ASS } \\
\text { (THIS REPURT) } \\
\text { UNC L. ASSIFIED }\end{array}$ & 21. NO. OF PAGES \\
\hline $\begin{array}{l}\text { 20. SF( URITY CLASS } \\
\text { (THISPACE) } \\
\text { I'N( I.ASSHIIED }\end{array}$ & 22. Price \\
\hline
\end{tabular}



S 


(4M) 
